\title{
Fundamental Study of Low-NOx Combustion Fly Ash Utilization
}

\author{
Semi-Annual Report \\ April 1 - September 30, 1997
}

\author{
By \\ R. H. Hurt; E. M. Suuberg; Y. M. Gao; W. D. Lilly \\ I Küloats; K. Smith; N. Sabanegh
}

Work Performed Under Contract No.: DE-FG22-96PC96213

\author{
For \\ U.S. Department of Energy \\ Office of Fossil Energy \\ Federal Energy Technology Center \\ P.O. Box 880 \\ Morgantown, West Virginia 26507-0880
}

By

Division of Engineering

Brown University

Providence, Rhode Island 02912 


\section{Disclaimer}

This report was prepared as an account of work sponsored by an agency of the United States Government. Neither the United States Government nor any agency thereof, nor any of their employees, makes any warranty, express or implied, or assumes any legal liability or responsibility for the accuracy, completeness, or usefulness of any information, apparatus, product, or process disclosed, or represents that its use would not infringe privately owned rights. Reference herein to any specific commercial product, process, or service by trade

name, trademark, manufacturer, or otherwise does not necessarily constitute or imply its endorsement, recommendation, or favoring by the United States Government or any agency thereof. The views and opinions of authors expressed herein do not necessarily state or reflect those of the United States Government or any agency thereof. 


\title{
FUNDAMENTAL STUDY OF LOW-NOX COMBUSTION FLY ASH UTILIZATION
}

\author{
SECOND SEMI-ANNUAL REPORT
}

REPORTING PERIOD: APRIL 1, 1997 - SEPTEMBER 30, 1997

R.H. HURT AND E.M. SUUBERG (PRINCIPAL INVESTIGATORS) Y.M. GAO AND W.D. LILLY (STAFF)

I. KÜLAOTS (Ph.D. CANDIDATE)

K. SMITH AND N. SABANEGH (UNDERGRADUATE ASSISTANTS)

REPORT ISSUED: $\quad$ NOVEMBER, 1997

DOE AWARD NUMBER:DE-FG22-96PC9621-023

ISSUING ORGANIZATION: DIVISION OF ENGINEERING BROWN UNIVERSITY

PROVIDENCE, RI 02912

REPORT PREPARED BY: T.M. SUUBERG

TEL. (401) 863-1420

FAX (401) 863-1157

"US/DOE Patent Clearance is not required prior to the publication of this document" 


\begin{abstract}
This study is principally concerned with characterizing the organic part of coal combustion fly ashes. High carbon fly ashes are becoming more common as by-products of low-NOx combustion technology, and there is need to learn more about this fraction of the fly ash. The project team consists of two universities, Brown and Princeton, and an electrical utility, New England Power. A sample suite of over forty fly ashes has been gathered from utilities across the United States, and includes ashes from a coals ranging in rank from bituminous to lignite. The characterizations of these ashes include standard tests (LOI, Foam Index), as well as more detailed characterizations of their surface areas, porosity, extractability and adsorption behavior. The ultimate goal is, by better characterizing the material, to enable broadening the range of applications for coal fly ash re-use beyond the current main market as a pozzolanic agent for concretes. The potential for high carboncontent fly ashes to substitute for activated carbons is receiving particular attention. The work performed to date has already revealed how very different the surfaces of different ashes produced by the same utility can be, with respect to polarity of the residual carbon. This can help explain the large variations in acceptability of these ashes as concrete additives.
\end{abstract}




\section{Table of Contents}

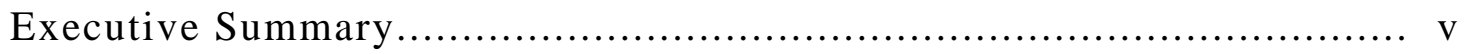

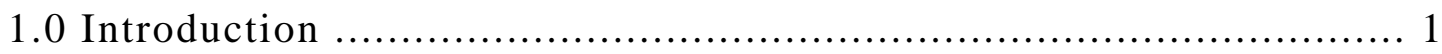

1.1 Project Description .............................................. 2

2.0 Progress During This Reporting Period......................................5

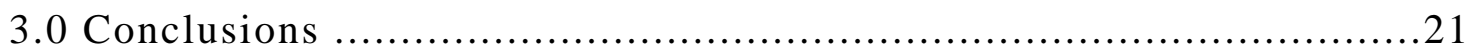

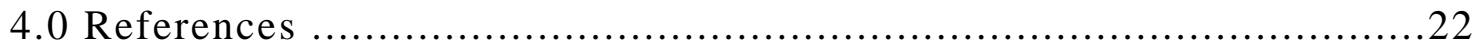




\title{
EXECUTIVE SUMMARY
}

\section{FUNDAMENTAL STUDY OF LOW-NOx COMBUSTION FLY ASH UTILIZATION (DE-FG22-96PC96213)}

\begin{abstract}
Background
The Nation faces a serious question concerning what to do with fly ash from coal-fired power stations. Only about $15 \%$ is presently utilized in cement and concrete products, which is by far the largest single market for this material. Since most of the remainder is landfilled, there is economic incentive for utilities to seek new opportunities for utilization. This project is concerned with better characterization of the fly ash, and identification of potential new uses of the ash. It is the "organic" portion of the ash, the unburned carbon, which may be the key to success in many new utilization schemes. The unburned carbon content has been significantly increased and altered by the introduction of new NOx control technology. The increased levels of carbon, and the different nature of the carbon, may offer new opportunities for ash re-utilization at the same time as these characteristics cause problems in concrete-based reuse.
\end{abstract}

\section{Project Overview}

This project involves a collaborative effort between two universities (Brown and Princeton) and an electric utility (New England Power). The goal is to provide a more basic understanding of the nature of the organic fractions of fly ash. Four specific tasks have been defined:

1. Characterization of the physical and chemical nature of ash organics. This task involves a) acquiring a suite of fly ash samples from utilities throughout the country, b) characterizing this set of samples, or a subset, with respect to organic (carbon and extractables) content, surface area and porosity. As part of this task, the oxidation reactivity of the unburned carbon is being measured.

2. Development of new screening tests to evaluate the samples with respect to various applications. This includes further development of a test for fine carbon content and identification of a simple alternative to the foam index test, both of which can serve as measures of suitability of the ash in concrete applications.

3. Characterization of the adsorption behavior of selected fly ashes relative to various organic and inorganic adsorbates.

4. Examination of the technical suitability of high-carbon coal fly ash as a low-cost alternative to activated carbon in adsorption applications.

\section{Progress to Date}

A suite of 48 samples, representative of utility practice across the country, has been assembled, and is being characterized as described in task 1 above. Tests of the adsorption behavior of the fly ashes have been performed, with an examination of the polar characteristics of their surfaces. This work has provided new insights into what determines whether a particular ash is suitable for concrete applications. The role of porosity in determining the adsorptive behavior of fly ashes has also been examined. The nature of the porosity of the carbons in fly ashes has received considerable attention during this reporting period. The oxidation reactivity of the residual carbon has also been examined for a broad range of samples. This reactivity does not seem to correlate well with the adsorption behavior of the carbon, but may provide insights into the nature of the carbons themselves. 


\subsection{INTRODUCTION}

The Nation's electric utilities produce an enormous amount of coal fly ash - recently about 48 million tons per year ${ }^{1}$. These utilities have long preferred recycling or reuse of the ash to landfill or pond disposal, but increasing landfill costs, liability concerns and other industry developments have shifted what was a mild preference for recycling to an imperative at many companies. At the present time, concrete products represent the major market for the ash, and consume about $1 / 6$ of the total produced ${ }^{1}$. Most of the remainder is presently landfilled. Many new market opportunities have been explored ${ }^{2}$, including lightweight aggregate, flowable fill, cement kiln feedstock, structural fill, alternate fuels, filtration media, ladle topping, fertilizer, casting sands and soil additives. To this list must be added sorbent applications, particularly for high carbon ashes from low- $\mathrm{NO}_{\mathrm{X}}$ combustion.

The widespread application of low- $\mathrm{NO}_{\mathrm{X}}$ combustion technologies has recently increased the carbon levels in fly ash at many utilities. In many instances, this has rendered the fly ash unsuitable for sale to the concrete industry ${ }^{3}$. Even in situations in which the carbon contents are within ASTM specifications, problems have still been reported with ashes from low- $\mathrm{NO}_{\mathrm{X}}$ combustion systems. Recent work at Brown University and New England Power has suggested that the problem might be related to changes in the form and sorptive properties of the carbon 4,5 . One of the goals of this project is development of a clearer understanding of what governs the performance of carbon-containing ash in concrete-type applications.

Unfortunately, most of the fundamental research on ash characterization has focused on the inorganic (majority) component of fly ash - its particle size, morphology, and chemical composition. It is the organic portion of the ash, consisting mainly of carbon, that could hold the key to success or failure in many new utilization schemes. It is the clearly significant role that carbon plays in concrete applications that has motivated the development of a variety of processes for carbon separation or removal from ash. These include processes based upon electrostatic separation, froth flotation, and carbon burnout outside the utility boiler. In the case of the 
separation schemes, streams considerably enriched in carbon (to tens of percent by mass) could become available. This may further expand the potential markets for application of the ash-derived materials to include some currently dominated by activated carbons, particularly powdered activated carbons.

In this project, Brown and Princeton Universities are teamed with New England Power to undertake a broad-based scientific investigation of the form, sorptive properties and behavior of the organic material in ash samples in order to help identify new commercial opportunities. The objectives of the research are to 1) thoroughly characterize the organic matter in ash with respect to form (including char-derived carbon, soot, and extractables), structure and surface properties, 2) examine the sorptive properties of ashes in technologically significant situations, and 3) to define new applications opportunities.

\subsection{PROJECT DESCRIPTION}

The project has been divided into four basic tasks, as outlined below. These tasks are being carried out by teams consisting of researchers from Brown, Princeton and New England Power. Project management is the responsibility of the team at Brown. Since the tasks have been described in some detail in the previous semi-annual report, they will be only briefly summarized here.

\section{Task 1- Physical and Chemical Characterization of Ash Organics.}

\section{Sample acquisition}

The first part of this task involves acquiring a suite of fly ash samples from utilities throughout the country. These are being selected on the basis of recommendations from utilities

and ash brokers, to be representative of "normal" practice as well as unusual situations.. Several extensively studied fly ash samples have been provided by New England Power. These have the advantage of having been prepared under relatively well-defined conditions. 


\section{Physical Characterization}

All samples are being characterized in-house at Brown with respect to organics content, carbon form and morphology, surface area, and porosity. The main characterization of organics content involves the standard loss-on-ignition (LOI) test.. Selected samples are being analyzed for extractables content by the team at Princeton. As part of another program at Brown, this set of data will be supplemented by the results of the "Foam Index" test, which is one of the key assays for suitability in concrete applications.

\section{Task 2- Analytical Technique Development}

There is a strong incentive to develop new screening tests to determine the suitability of coal fly ashes for concrete applications. To qualify as a concrete additive, a fly ash must as a minimum meet the ASTM C618 standards, including one prescribing, generally, that the ash not exhibit more than 6 wt.\% loss on ignition (LOI). These standards are, however, not generally sufficient to ensure good performance, and have been superseded by even more stringent local regulations on LOI.

In addition, samples of fly ash must typically be tested for performance with respect to specific key additives in the concrete, the so-called Air Entraining Admixtures (AEAs). The AEAs are used to ensure that the final concrete will contain sufficient numbers of air bubbles, of the proper size, in order to impart good workability and freeze-thaw resistance to the concrete. The test used for this purpose is the "Foam Index" test, in which the required amount of AEA is measured in what is essentially a titration test, the endpoint of which is determined by the stability of the foam created in a water solution of the AEA, which is a surfactant (see ref. 4-6

The recent work at Brown has strongly suggested that the unburned carbon is acting an adsorbent relative to the (organic) AEA surfactants. This work indicated that surface area of the unburned carbon in the fly ash is a key criterion in determining AEA requirements in the Foam Index test $t^{4,5}$. Soot has recently been identified (using electron microscopy) in some samples from low- $\mathrm{NO}_{\mathrm{X}}$ firing. Soot particles would offer a much different surface area per unit mass of carbon 
than does unburned char. This has led to proposal of a new test to characterize the nature of the carbons in fly ash based upon fine particle content of the $\mathrm{ash}^{4}$. This new test is referred to as the Gao Fine Particle test. It is the purpose of this task to develop this new fine particle test further, in order to determine whether it can be a useful supplement to the other tests already in use.

Finally, some development work will be undertaken to define a more fundamental sorption test, which will be more readily interpretable and more reproducible than the industry-standard Foam Index test.

\section{Task 3- Adsorption Experiments Involving Strategic Compounds}

This work, being conducted at Brown, is investigating the sorptive behavior of ash organics (carbon), and the results will allow prediction of ash interactions with aqueous wastes, organic wastes, air toxic vapors, and air entraining admixtures in concrete. Testing will be performed in both water and air, to evaluate potential for purification applications in both media. An important characteristic of the ash carbons will be whether they have hydrophilic or hydrophobic surfaces. This will be determined both by measuring water vapor sorption isotherms, as well as by using new adsorption calorimetry methods 7 (see below). The adsorptive capacity of the surface for non-polar organic vapors will be determined by use of propane or butane, employing a recently described temperature programmed methodology 8 . Similarly, a model aromatic adsorbate, such as benzene or toluene, a basic adsorbate, such as ammonia or propyl amine, and a chlorinated hydrocarbon such as carbon tetrachloride, will be examined, with respect to vapor sorption capacity and kinetics. The suitability for water purification will be examined by experiments in which various components are partitioned onto the carbon from water. The experiments already under way with AEA compounds will provide some guidance as to selection of candidate ashes. The so-called "bottle point" method" can be used to examine the uptake of water contaminants such as p-nitrophenol or phenol, which can serve as reasonable (and widely used) benchmarks of performance. 


\section{Task 4- Comparative evaluation against commercial activated carbons.}

In most of the applications considered for high-carbon ash, it competes directly with commercial activated carbons - materials that offer better performance but at a much higher cost. It is critical for the economic evaluations to have direct comparisons between the new materials (fly ash streams) and accepted commercial products. As a final task, we will therefore compile a summary of relevant information on commercial carbons, and to critically assess the performance of the fly ash streams against these competing materials.

\subsection{PROGRESS DURING THIS REPORTING PERIOD}

The project is well under way, and a number of results from the project have already been presented at conferences. Two recent presentations have been made at the 1997 International Conference on Coal Science ${ }^{10}$ and the 1997 International Fly Ash Utilization Symposium ${ }^{11}$. Results from the latter will be summarized below. In addition to the work being performed by the original project team, there have been new contacts made with a DOE team interested in the characterization of some of the samples. In particular, a few samples which have been characterized at Brown have been recently provided to FETC/DOE researchers (Drs. Dennis Finseth and Malvina Farcasiu of the Pittsburgh center). These samples are being explored with respect to their possible catalytic activity, and are being examined using XPS techniques. We hope to hear about results from these studies in time for the next report

The sample bank, which was described in the previous report has been expanded. Since the problems caused by variations in unburned carbon are experienced nationwide, but the nature of the ashes from different utilities vary widely, it would be dangerous to focus this study too narrowly. Thus while the interests and experience of New England Power will continue to be important in guiding the search for viable commercial applications, our sample bank reflects a wide range of actual operations.

The current makeup of the sample bank is shown in Table 1. 
Table 1. Fly Ash Sample Bank.

\begin{tabular}{|c|c|c|}
\hline $\begin{array}{c}\text { Sample } \\
\text { No. }\end{array}$ & LOI & 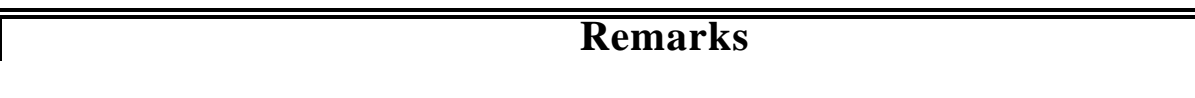 \\
\hline 1 & 2 & 3 \\
\hline$\overline{\overline{\text { FA1 }}}$ & 6.5 & NEP - Brayton pt., Unit \#3, \#3E, unprocessed, problem ash \\
\hline FA2 & 3.1 & NEP - Brayton pt., Unit \#3, from STI, unprocessed, problem ash \\
\hline FA3 & 14.6 & NEP - Brayton pt.,Silo \#2, \#2D+E unprocessed, good ash \\
\hline FA4 & 14.6 & NEP - Brayton pt., Unit \#2, unprocessed \\
\hline FA5 & 1.9 & NEP - Brayton pt., Unit \#3, pre low-NOx conversion, good ash \\
\hline FA6 & 3.4 & NEP - Brayton pt., poor air entrainment (Tresca 5252) \\
\hline FA7 & 2.6 & NEP - Brayton pt., (BPP 50612-260,T24), problem ash, from STI \\
\hline FA8 & 3.8 & NEP - Brayton pt., (BPP 50612-261,T34), poor air entrainment \\
\hline FA9 & 65.3 & NEP - Brayton pt., black in color, from STI \\
\hline FA10 & 2.6 & NEP - Brayton pt., (BPM 50802-4) from STI \\
\hline FA11 & 2.5 & NEP - Brayton pt., (BPP 50612-262, T11), from STI \\
\hline FA12 & 2.3 & NEP - Brayton pt., (BPP 50610-258, T23), from STI \\
\hline FA13 & 3.8 & NEP - Brayton pt., (BPP 50612-261, T34), same as FA8, from STI \\
\hline FA16 & 1.5 & Helsinki (50703-136, E1), very bad ash, from STI \\
\hline FA19 & 3.6 & NEP - Brayton pt., Unit \#3, ash with 5\% Gas co-firing \\
\hline FA20 & 2.0 & NEP - Brayton pt., white-gray ash, problem ash, from STI \\
\hline FA21 & 6.1 & NEP - Brayton pt. \\
\hline FA22 & 33.6 & NEP - Salem Harbor ash, unprocessed \\
\hline FA23 & 65.5 & NEP - Salem Harbor ash, processed \\
\hline FA24 & 2.7 & AEP-Columbus, Silo \#2, Unit \#1, from Eastern Bituminous, good ash \\
\hline FA25 & 2.5 & AEP-Columbus, Silo \#4, Unit \#2, same as FA24 \\
\hline FA26 & 4 & AEP- Columbus Mountaineet Plant, Silo \#2, problem ash \\
\hline FA27 & 0.2 & $\begin{array}{l}\text { AEP, Rockport Plant (R.\#2) Regular ash from Powder River Basin coal } \\
\text { good ash }\end{array}$ \\
\hline FA28 & 2.4 & $\begin{array}{l}\text { same as FA27, except produced from a feed stream containing } \\
5 \% \text { Petroleum Coke }\end{array}$ \\
\hline FA29 & 1.5 & AEP, Clinch River Plant, Virginia Coal, $3 \% \mathrm{CaO}$ but Class $\mathrm{F}$ \\
\hline FA30 & 35.1 & NEP - Brayton pt., High Carbon Fly Ash \\
\hline FA31 & 0.9 & NEP - Brayton pt., Low Carbon Fly Ash \\
\hline FA32 & 44.7 & HEL 60520 B-3-E-2, from STI \\
\hline FA33 & 29.1 & HEL 60517 B-6-E-2, from STI \\
\hline FA34 & 4.9 & BP 51103 B3 Feed, from STI \\
\hline FA35 & 17.5 & Petroleum Coke-western coal blended fuel \\
\hline FA36 & 0.3 & $\begin{array}{l}\text { "NA" Salt River Project, Navajo Station, Page Arizona, Subbit. Coal } \\
\text { from Black Mesa mine, Az, class F ash }\end{array}$ \\
\hline FA37 & 4.9 & $\begin{array}{l}\text { "CH" Public service of Colorado, Cherokee Station, either Subbit. } \\
\text { or Bituminous class F ash }\end{array}$ \\
\hline FA38 & 0.2 & "PAW" Public service of Colorado, Powder River Basin, class C ash \\
\hline FA39 & 0.8 & $\begin{array}{l}\text { "MO" Southern California Edison, Mojave Station, Nevada, subbit. } \\
\text { coal from Black Mesa mine, AZ }\end{array}$ \\
\hline FA40 & 1.1 & Welsh Power Plant, North-Easth Texas, 245620, class C Fly Ash \\
\hline FA41 & 1.1 & Welsh Power Plant, Texas, 245713, class C Fly Ash \\
\hline FA42 & 0.6 & Welsh Power Plant, Texas, 245716, class C Fly Ash \\
\hline
\end{tabular}




\begin{tabular}{|r|r|l||}
\hline FA43 & 0.6 & Flint Creek Plant, Arkansas, 213483, class C Fly Ash \\
\hline FA44 & 0.6 & Flint Creek Plant, Arkansas, 213491, class C Fly Ash \\
\hline FA45 & 0.7 & Flint Creek Plant, Arkansas, 22497, class C Fly Ash \\
\hline FA46 & 11.1 & NEP - Salem Harbor ash, July 1997 \\
\hline FA47 & 41.5 & NEP - Salem Harbor ash, Separated high Carbon, 1997 \\
\hline FA48 & 1.4 & NEP - Brayton pt., Separated low Carbon, July 1997 \\
\hline
\end{tabular}

Since the samples were obtained from various commercial sources, and there might be significant variability in composition during normal operations, all samples were rechecked for LOI using the standard ASTM method (Standard No. D3174-82). Some discrepancies, relative to the supplied LOI values, were encountered, though there was generally good agreement with the values supplied with the samples. All samples were subjected to replicate LOI determinations. It was noted that when reported LOI values were less than $1 \%$, large uncertainties were possible. Efforts have been made in these cases to check the standard LOI method against measurements performed in a thermogravimetric analyzer (TGA). The procedures were described in the previous report.

Table 1 shows that a broad range of samples has been assembled, exhibiting a wide range of LOI values. It should be noted that some samples are not necessarily typical of current utility practice. There are samples (e.g., FA9, FA23) which have been deliberately enriched in carbon content by an electrostatic separations process developed for New England Power by Separations Technology, Incorporated (STI) of Needham, Massachusetts. There are likewise samples that have been prepared in situations in which petroleum coke has been co-fired with coal (FA28 and FA $35)$.

Work has begun on characterization of the ash samples with respect to porosity. This porosity exists mainly in the carbon phase, and is important because of the large amount of surface area that this porosity contains; it is this surface that is responsible for AEA adsorption, and which could be useful in other desirable adsorption applications for the ash.

The principal porosity analysis technique employed during this reporting period was gas adsorption, using nitrogen and carbon dioxide. Full isotherms are being measured for all samples 
at $77 \mathrm{~K}$ using $\mathrm{N}_{2}$ and at $195 \mathrm{~K}$ using $\mathrm{CO}_{2}$ in selected samples. In addition to the usual BET and Dubinin-Radushkevich surface areas which are available from these measurements, full isotherms are being used to estimate micropore size distributions. These data will be later supplemented by measurements on meso- and macropore size distributions, to be obtained using mercury porosimetry.

\section{Characterization of the nature of the carbon surface}

Traditionally, LOI has been the most important parameter for making predictions of the performance of fly ash carbons in concrete. Again, the reason had to do with the efficacy of carbon in adsorbing AEAs. As noted above, the laboratory scale test of this efficacy has been the "Foam Index" test. The higher the Foam Index, the worse the performance in the field was likely to be. The results for tests performed on our sample suite are shown in Figure 1.

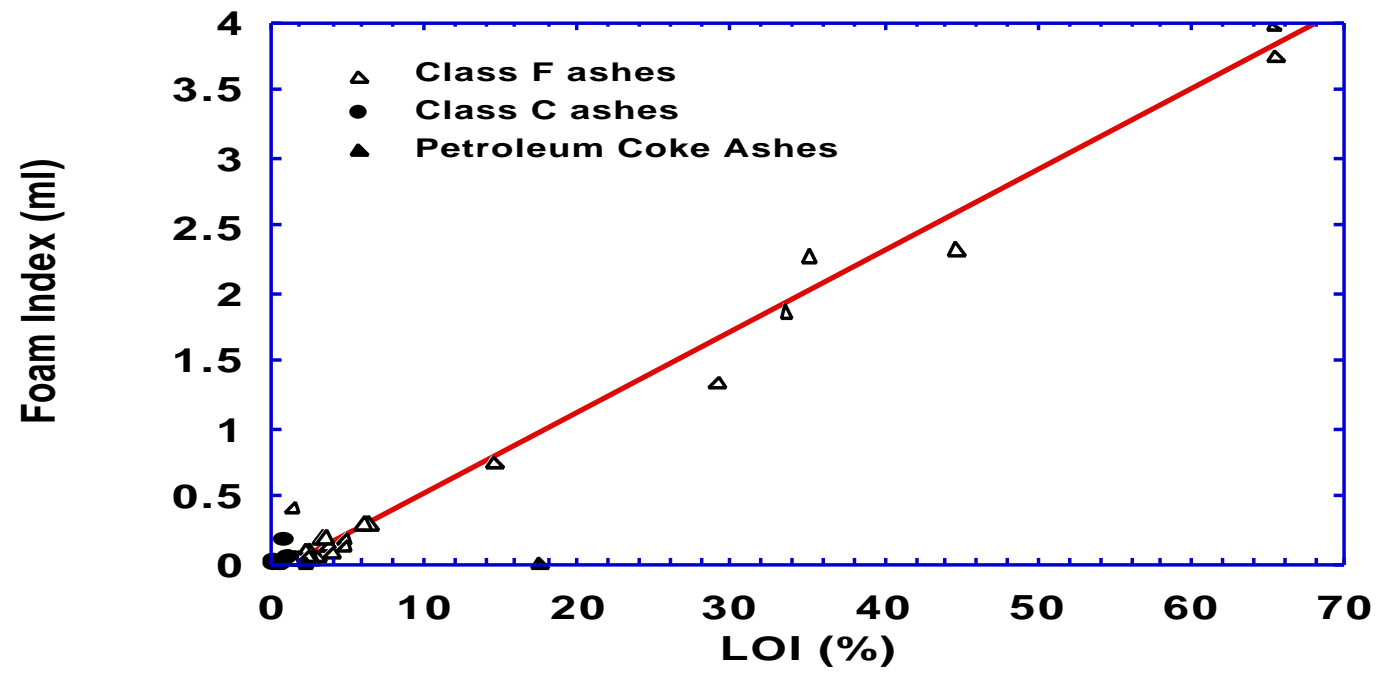

Figure 1. Correlation of Foam Index and LOI for different kinds of fly ash.

The details of the Foam Index test have been provided in the previously semi-annual report. To briefly summarize, the test involves what amounts to a titration of the fly ash with the AEA (surfactant), measuring the volume of AEA taken up until stable bubbles are achieved (as is desired 
in concrete). The units of Foam Index are somewhat arbitrary, as different workers use different conditions, but the results may be examined on a relative basis.

The correlation of Figure 1 is deceptively good, as it tends to emphasize the contribution of fly ashes which are far outside the realm of commercial acceptability. According to ASTM guidelines, fly ashes containing more than $6 \%$ LOI generally cannot be used in concrete, and even stricter standards have been developed by many state agencies. Thus the range of commercial interest is in the lower left corner of the figure. It is within this subset of samples that most of the subtle commercial problems have been encountered. A more revealing representation of the same data is shown in Figure 2.

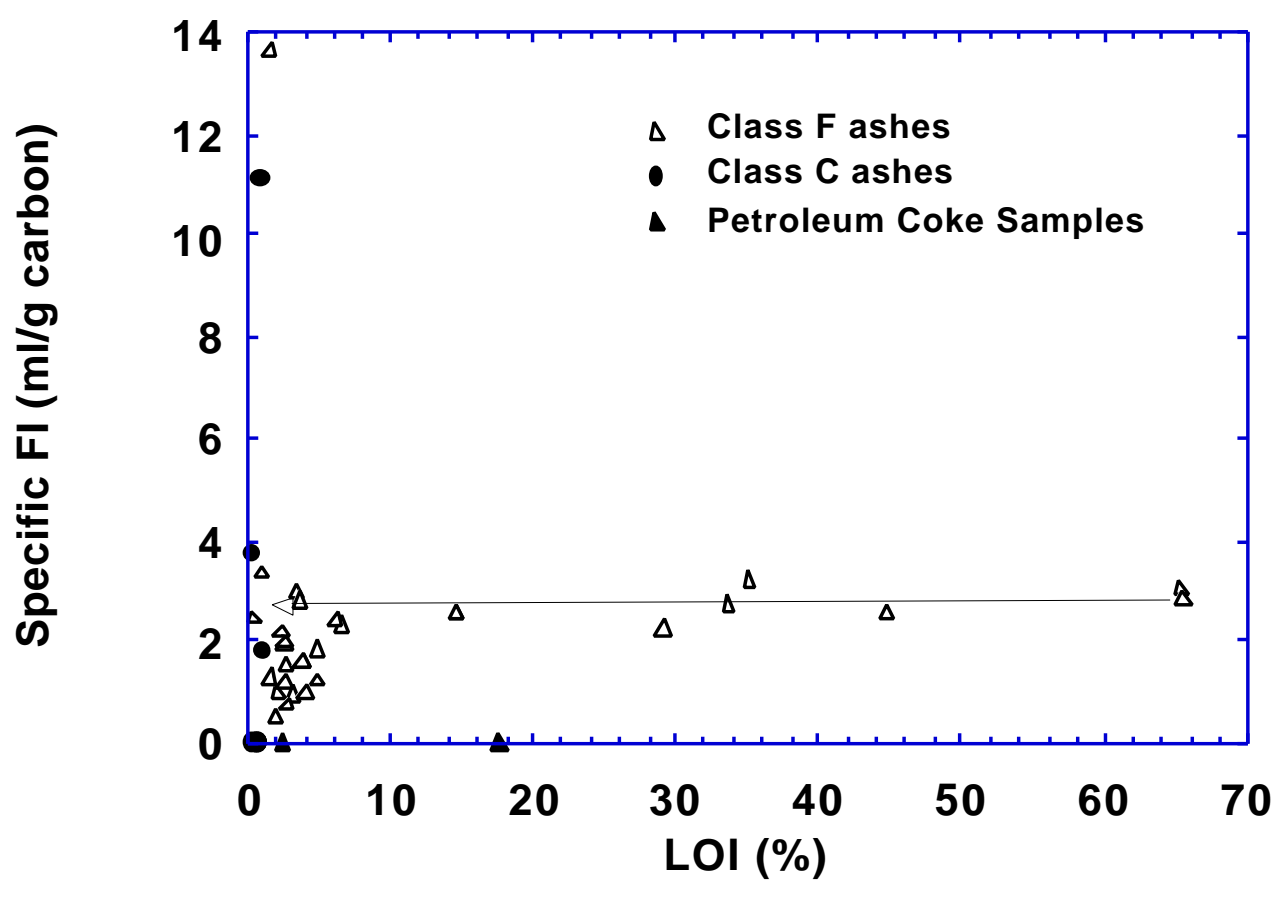

Figure 2. The data of Figure 1, represented as specific foam index.

In Figure 2, the data are shown as specific foam index, defined as the uptake of AEA per unit mass of carbon. This has the effect of emphasizing the differences in the low LOI samples. 
The high LOI samples fall at a relatively constant value of specific foam index, as indicated by the horizontal line. This could have been anticipated from the good correlation of Figure 1.

Part of the explanation for why certain carbons are more effective at adsorbing AEAs than are others has to do with differences in surface area per mass of carbon. This issue was discussed at length in our previous publications ${ }^{4,5}$. The fact that this explanation is only partially complete has been highlighted in the previous report, and is illustrated by the data of Figure 3.

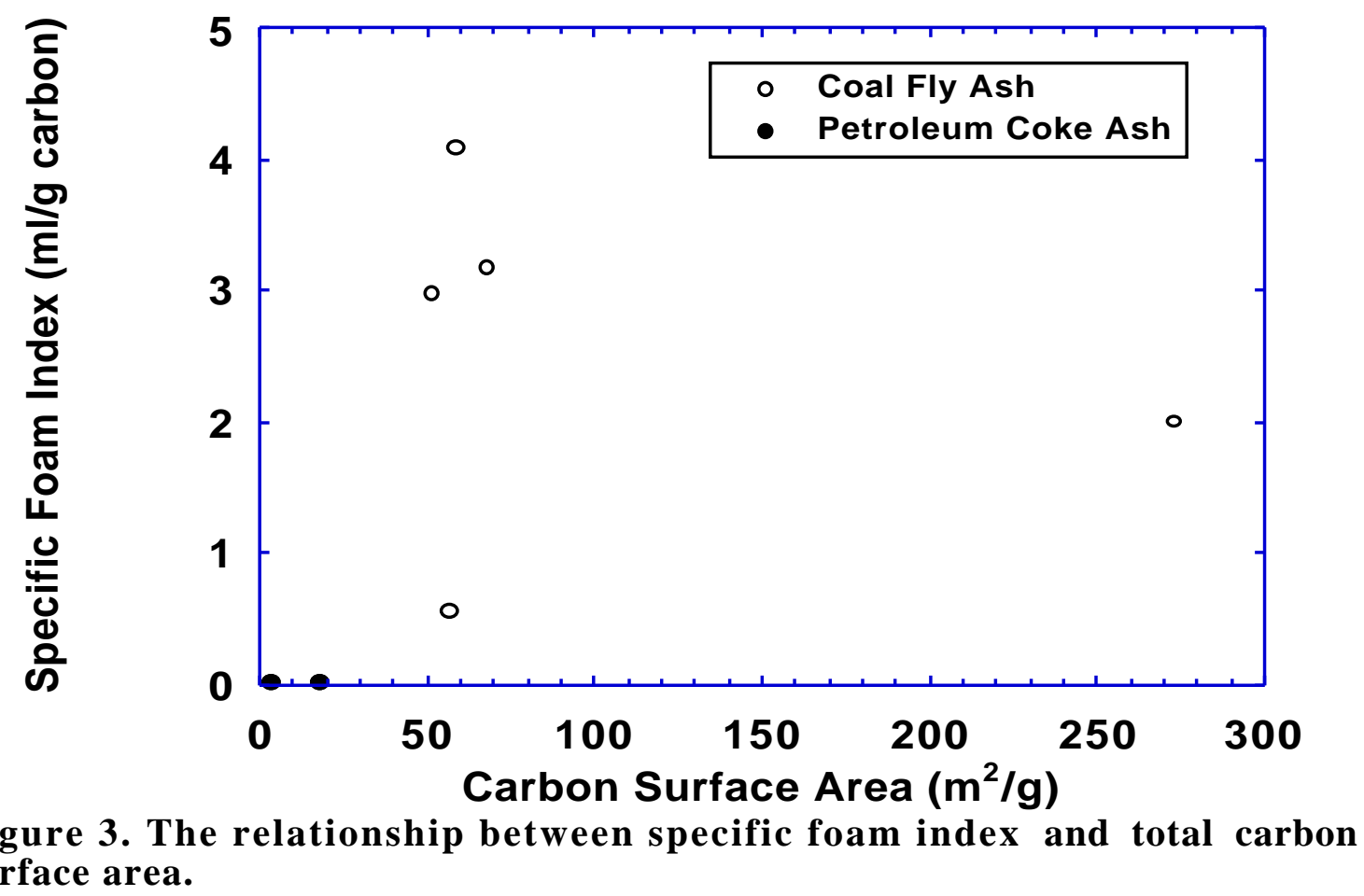

Figure 3 presents data and compares the surface area of the carbon fraction of the ash with the specific foam index. The carbon surface area was computed from nitrogen adsorption isotherms, using the BET equation. Surface areas were measured for the whole ashes, and then allowance was made for the surface area of the mineral fraction (generally determined to be about $0.7 \mathrm{~m}^{2} / \mathrm{g}$, and assumed to be that value for all samples). The resulting carbon-only surface area was divided by the mass of carbon in the sample, to obtain the plotted values. 
The petroleum coke-containing samples exhibit very low surface areas, and adsorb very little AEA. On the other hand, several of the class F coal fly ashes, which have carbon surface areas of between 50 and $70 \mathrm{~m}^{2} / \mathrm{g}$, vary widely in their ability to adsorb AEAs, despite their similarity in surface areas. There is clearly still a factor which is unaccounted for by an explanation based upon either LOI or surface area.

It has been noted that the nature of a carbon surface can determine its efficacy in adsorbing AEAs. Oxidized surfaces did not appear to adsorb as much AEA as did unoxidized surfaces ${ }^{4}$. This is not surprising, since AEAs are essentially saponified resins and detergent-like surfactants, containing polar endgroups and quite likely long non-polar chains. The non-polar parts of the AEAs are critical to stabilizing the bubbles in the otherwise polar medium of the concrete mix; these parts of the AEA molecules gather at the air-water interface. The inorganic ash components, cement, and water are all polar, while only the carbon surfaces, and in particular, unoxidized carbon surfaces, are non-polar. The greater the amounts of non-polar carbon surface, the more effectively adsorption of the AEA by carbon will compete with the intended role of stabilizing bubbles.

The above hypothesis was tested in work described in the previous reporting period, and recently presented elsewhere ${ }^{11}$. This work verified that there appears to be a correlation with the polar nature of the carbon surface; the more polar the carbon surface, the less AEA adsorption was measured.

Surface area alone might also not be a sufficient indicator of the ability to adsorb a given species, if that surface area is located in pores which are very difficult to access because of their small size. This issue was also examined during the previous reporting period, and was judged to not be as important as surface polarity, in the samples which were examined. The absence of a difference in the diffusional timescales for different particle sizes implied that the main locus of mass transfer resistance is within the particles. This is consistent with the microscopic images of the particles showing existence of numerous macropores in the carbon. These serve to feed the meso- and micro-pores, and the relevant diffusional length scale is presumably defined by the 
spacing between these large feeder pores. This spacing is naturally unaffected by the variation of particle size on a scale which is at least an order of magnitude larger. The practical implication of slow diffusion is that if a sample containing marginally accessible porosity is encountered in practice, it might provide an acceptable "Foam Index" result on the normal timescale of that test, but then later fail due to adsorptive loss of AEA at longer times. There are anecdotal reports of such behavior from the field.

\section{Characterization of the Porosity in Fly Ash Carbons}

Figure 4 shows standard nitrogen adsorption isotherms obtained on the sample FA 6 in an as-received condition, as well as the isotherms obtained on the same fly ash after the carbon was all burned off at approximately $700^{\circ} \mathrm{C}$ for 2 hours.

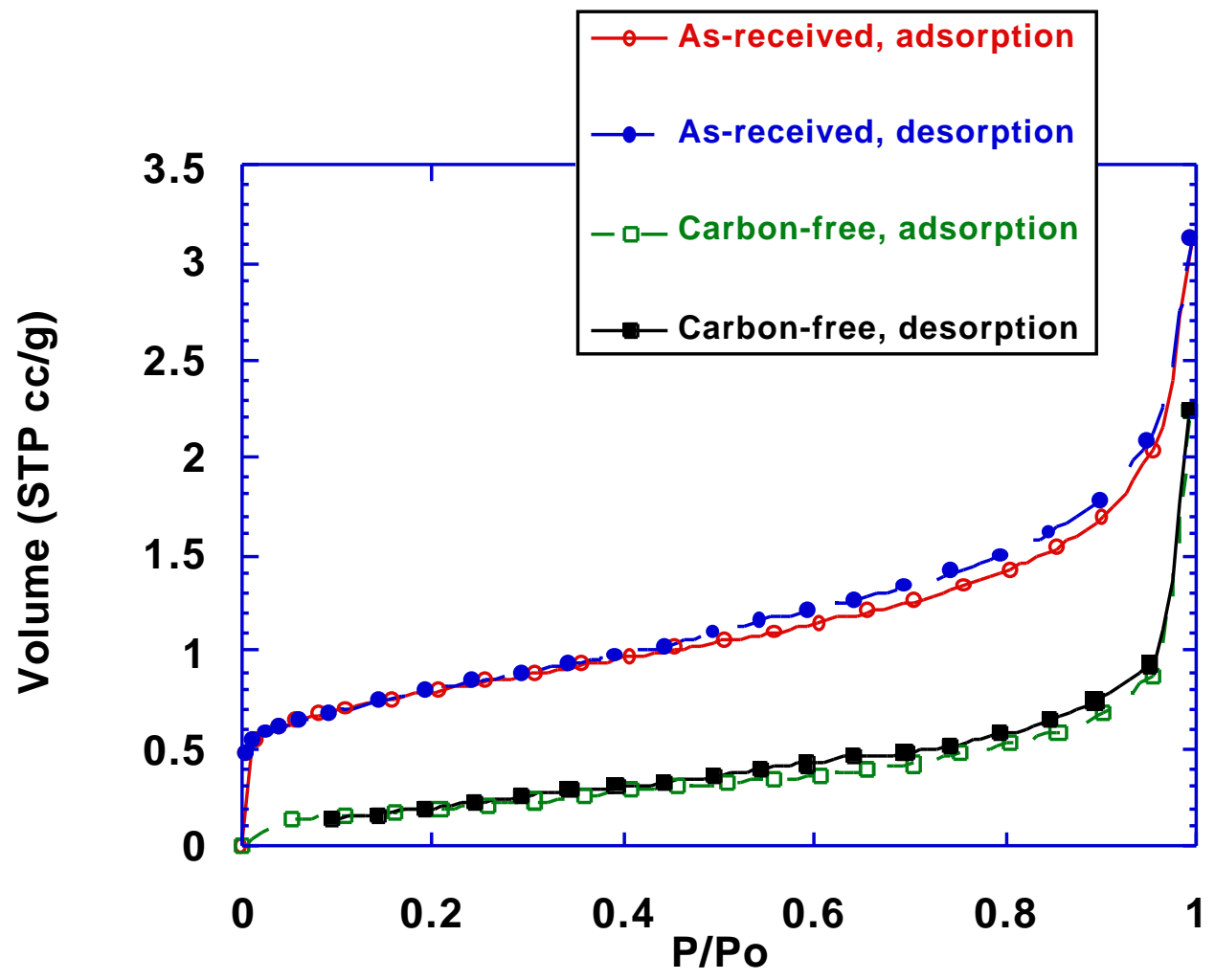

Figure 4. Nitrogen isotherms obtained at $77 \mathrm{~K}$ on sample FA 6 in an as-received condition, and following removal of its carbon. 
There are several features of the isotherms of Figure 4 which warrant noting. The first is that the isotherm for the sample which is carbon-free exhibits very little microporosity. The isotherm appears to be mainly of Type II character ${ }^{12}$. There is little uptake of nitrogen (here shown as nitrogen uptake volume in $\mathrm{STP} c \mathrm{~g} / \mathrm{g}$ ) at low values of $\mathrm{P} / \mathrm{P}_{0}$. This type of isotherm is mainly associated with adsorption by nonporous solids. If there is porosity, it is in the mesopore and macropore regime. The fact that there is a very slight hysteresis behavior between adsorption and desorption curves is suggestive of a small amount of mesoporosity. All of these observations are entirely consistent with what is known about the mineral matter in class F coal fly ash - most is present as small non-porous glassy spheres. The sharp rise in the isotherms at near $\mathrm{P} / \mathrm{P}_{0}=1$ might be simply reflecting capillary condensation between the very small fly ash spheres.

The isotherms for the as-received fly ash are very different from those for the carbon-free fly ash. The steep rise near $\mathrm{P} / \mathrm{P}_{0}$ is strong evidence for the existence of micropores in the sample. The isotherm has begun to take on a Type I character ${ }^{12}$. Application of the BET equation to the asreceived sample yields a surface area of approximately $2.7 \mathrm{~m}^{2} / \mathrm{g}$, in contrast to the $0.7 \mathrm{~m}^{2} / \mathrm{g}$ for the carbon-free sample. It was already noted in the previous semi-annual report that the majority of surface area is found in the carbon, despite the fact that it is present only to an extent of $3.4 \%$ by mass. It is this microporous area which provides the active surface for adsorption of the AEA. These isotherms are very typical of what is seen in many fly ashes.

Since it is the behavior of the carbon which is of greatest interest, the above isotherm results have been recalculated to a mass of carbon basis. The results are shown in Figure 5. The results for FA 6 have been calculated by subtraction of the contribution of the mineral components from the isotherm for the as-received material. The results for FA 9 and FA 23 are also shown for comparison. These two fly ashes contain much higher amounts of carbon (LOI is about $66 \%$ for each). There is a remarkable similarity in the trends exhibited by these three samples, despite the enormous difference in carbon contents. It is believed that all three samples come from similar bituminous coals (fuel switching made exact identification problematic), burned in different units, 
and in two cases enriched by separation. All show very similar degrees of microporosity, and with that, very similar surface areas on a carbon basis.

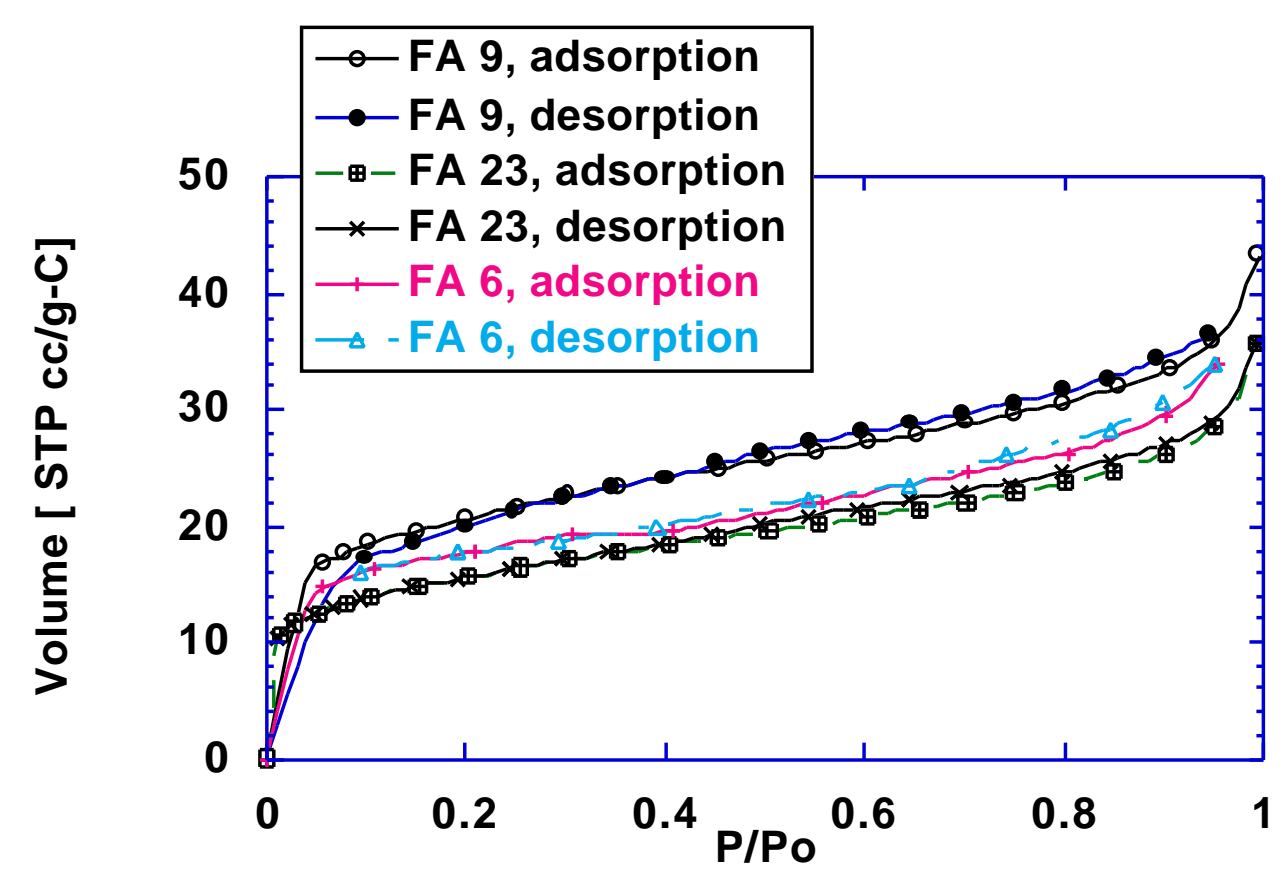

Figure 5. Nitrogen sorption isotherms obtained on three different fly ash carbons. All are calculated on the basis of nitrogen sorption volume per mass of carbon present in the sample.

The surface area for the FA 6 is approximately $60 \mathrm{~m}^{2} / \mathrm{g}$, that for FA 23 is $53 \mathrm{~m}^{2} / \mathrm{g}$, and that for FA 9 is $68 \mathrm{~m}^{2} / \mathrm{g}$. Again, the surface area is clearly dominated by micropores, and the isotherms are strongly Type I as a result. The interesting implication of this observation is that despite differing extents of carbon burn-out in the different fly ash samples, the nature of the porosity does not change very drastically with burn-out (at least when the same or similar coals are used).

It is not the case that all carbons which pass through a boiler have a similar particle morphology. This is well-known, and can also be demonstrated using gas adsorption techniques. Figure 6 shows a comparison of the data for FA 6 with the data for FA 35, which is a sample produced from co-firing petroleum coke with coal. In the latter case, most of the carbon which survives the boiler comes from the petroleum coke. 


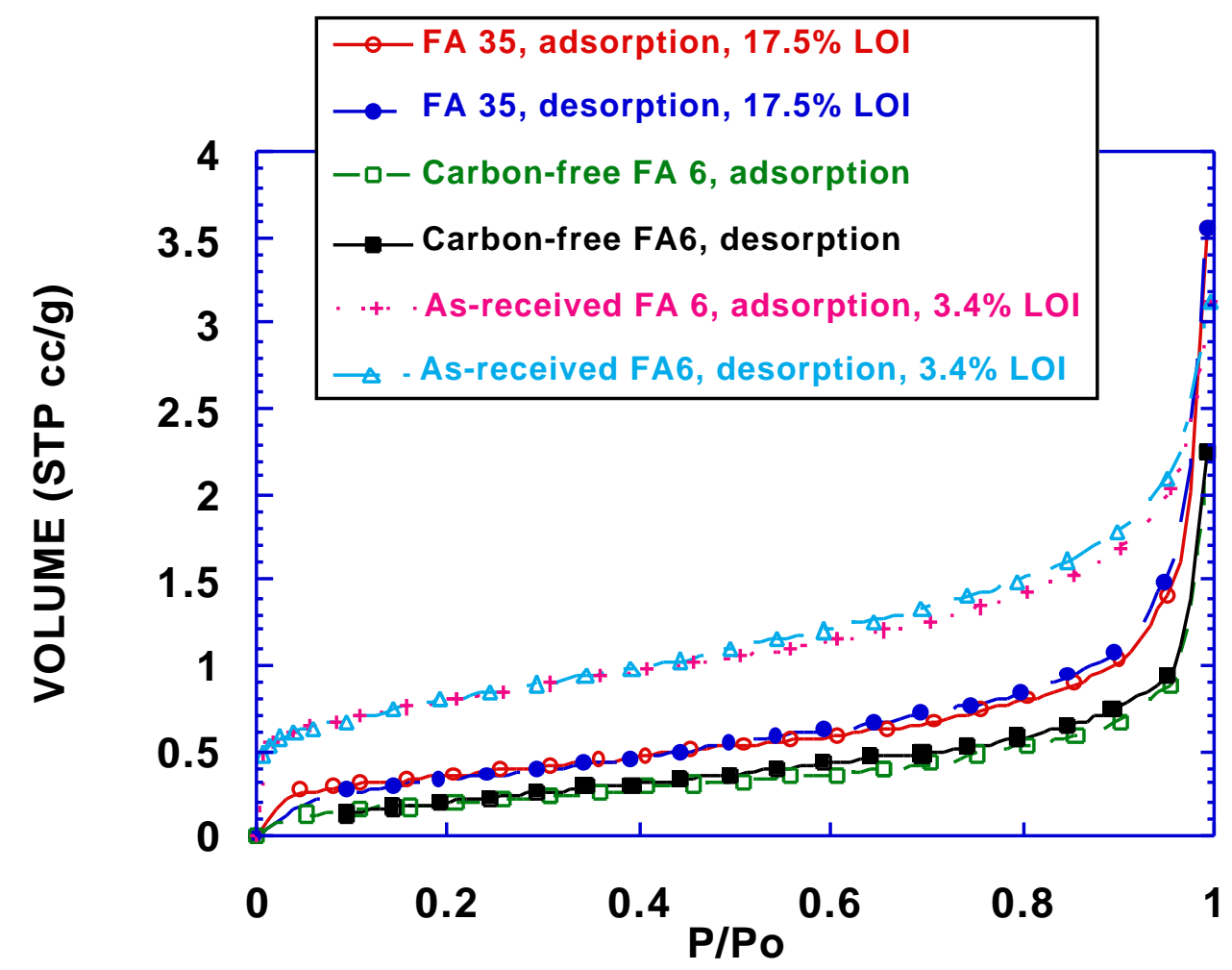

Figure 6. A comparison of the nitrogen isotherms obtained with sample FA 6 (ordinary class F fly ash) with those obtained with FA 35 (petroleum cokecontaining fly ash).

In spite of the considerably higher content of carbon in FA 35, its isotherm behavior is quite similar to that of the FA 6 which contains no carbon. In effect, the carbon of FA 35 is not available to participate in adsorption. This is borne out by the observation that the foam index of this sample is very nearly zero, and illustrates again the potential pitfalls is using an LOI-based criterion for judging the adsorption potential of a particular sample.

During the last reporting period, the very large differences in both field performance and foam index of otherwise similar samples FA 5 and FA 6 was attributed to the difference in surface polarity of these samples. Figure 7 compares the nitrogen isotherms of these two samples, and confirms that there is no evidence of significant difference on this basis. 


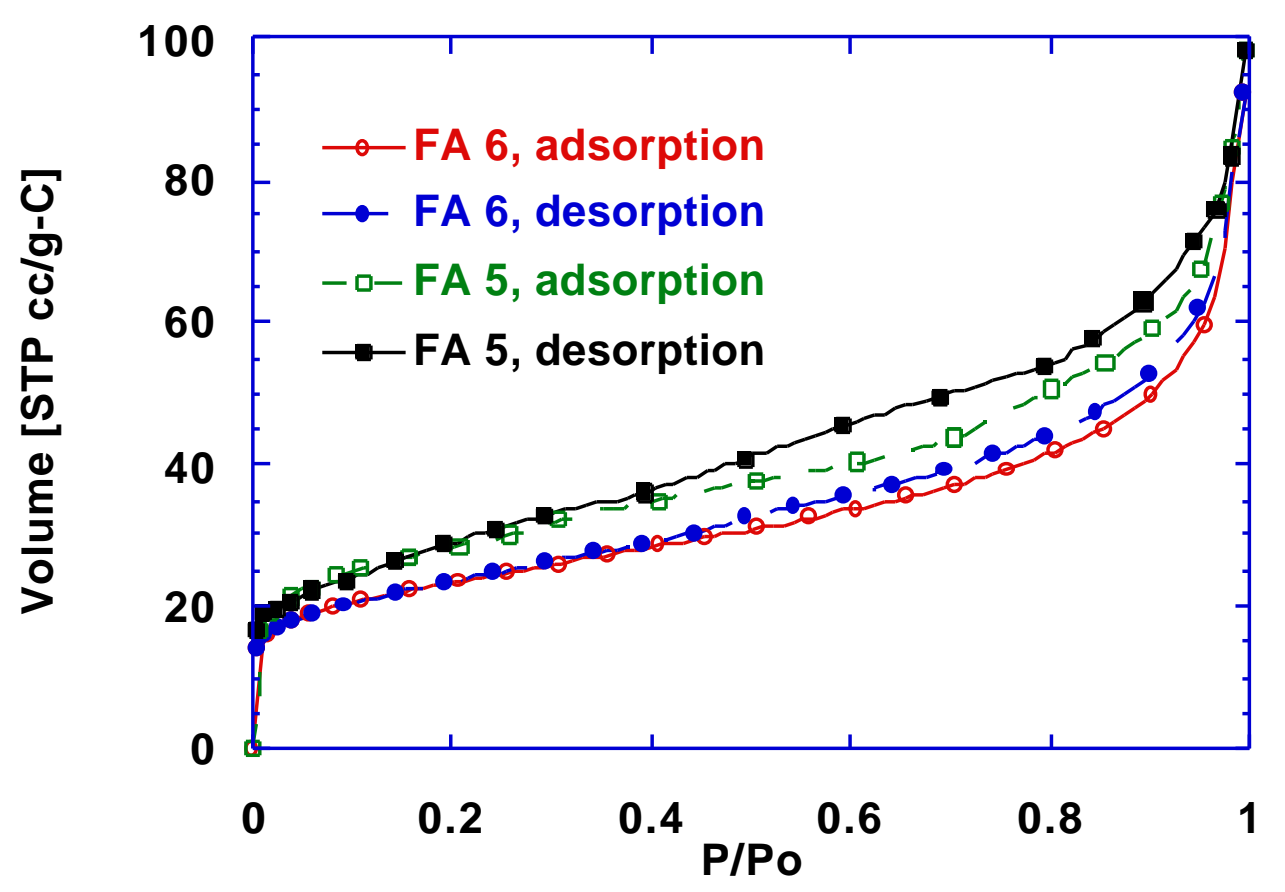

Figure 7. A comparison of nitrogen isotherms obtained on FA 5 (low foam index) and FA 6 (high foam index) calculated on a mass of carbon basis.

It should be noted that in this case, since there were no data available for carbon-free FA 5, the correction to a mass of carbon basis involved simply dividing the adsorption volume by the fractional LOI. A consistent calculation was performed for FA 6, which explains a small difference between the values seen in this figure and those in Figure 5.

Finally, there are sometimes concerns expressed in the literature about the use of nitrogen for characterization of porosity of carbons. This is particularly seen in the literature pertaining to characterizing porosity in coals themselves. Often, carbon dioxide has been recommended as a better characterization adsorbate, because of concerns about activated diffusional processes in small pores. Generally speaking, nitrogen is the better choice for characterizing microporosity in carbons which have been burned off to a significant extent ${ }^{13}$. The reason has to do with the inability of the 
$\mathrm{CO}_{2}$ to completely fill pores larger than medium-sized micropores. The comparison of the isotherms obtained in the different gases is presented in Figure 8.

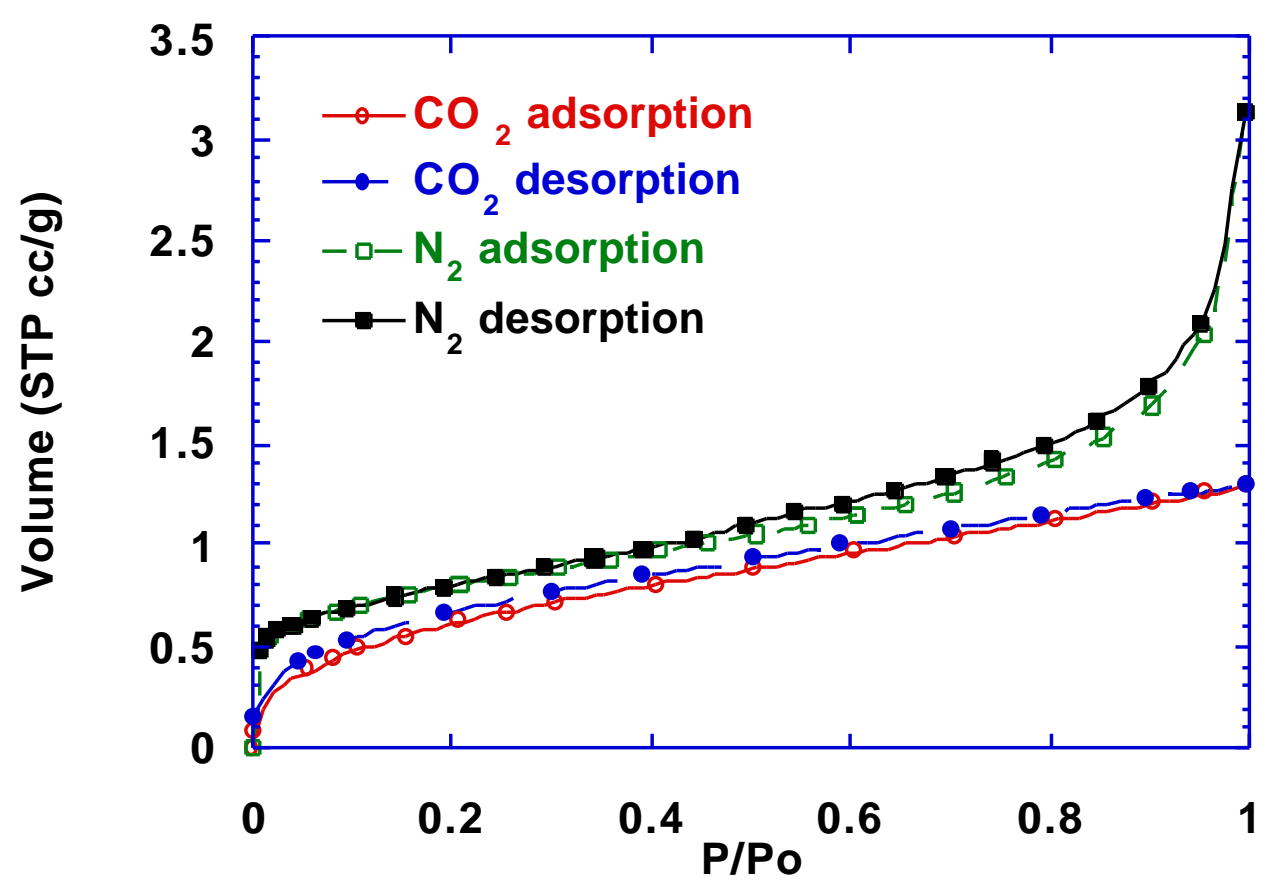

Figure 8. A comparison of nitrogen (77 K) and carbon dioxide (195 K) isotherms on FA 6.

The nitrogen isotherm reveals a larger extent of microporosity, and shows bulk capillary condensation, in macropores and between particles, which the carbon dioxide cannot reveal. Thus nitrogen isotherms will generally be preferred during the course of this study.

The Oxidation Reactivity of Carbon in Fly Ash

As part of the routine characterizations of samples, the reactivity of the samples towards oxidation has been measured using a non-isothermal technique. The technique is based upon one 
developed elsewhere ${ }^{14}$. The method involves tracking the oxidative weight loss from a carbon sample using a TGA device. The sample is heated at a rate of $30 \mathrm{~K} / \mathrm{min}$ in a flow of oxidizing gas. The experiments were performed in air ( $21 \%$ oxygen). The reactivity characterization parameter was selected to be $T_{c r}$, the so-called "critical temperature", which was defined as in ref. 14 to be the temperature at which the mass loss rate becomes $0.065 \mathrm{~g} / \mathrm{g} \bullet \mathrm{min}$. This low rate of mass loss was selected so as to be in the intrinsic rate regime, but still be easily measurable. The results of testing the majority of samples in the sample suite is shown in Figure 9, plotting the temperature at which $10 \%$ mass loss is achieved against $\mathrm{T}_{\mathrm{cr}}$.

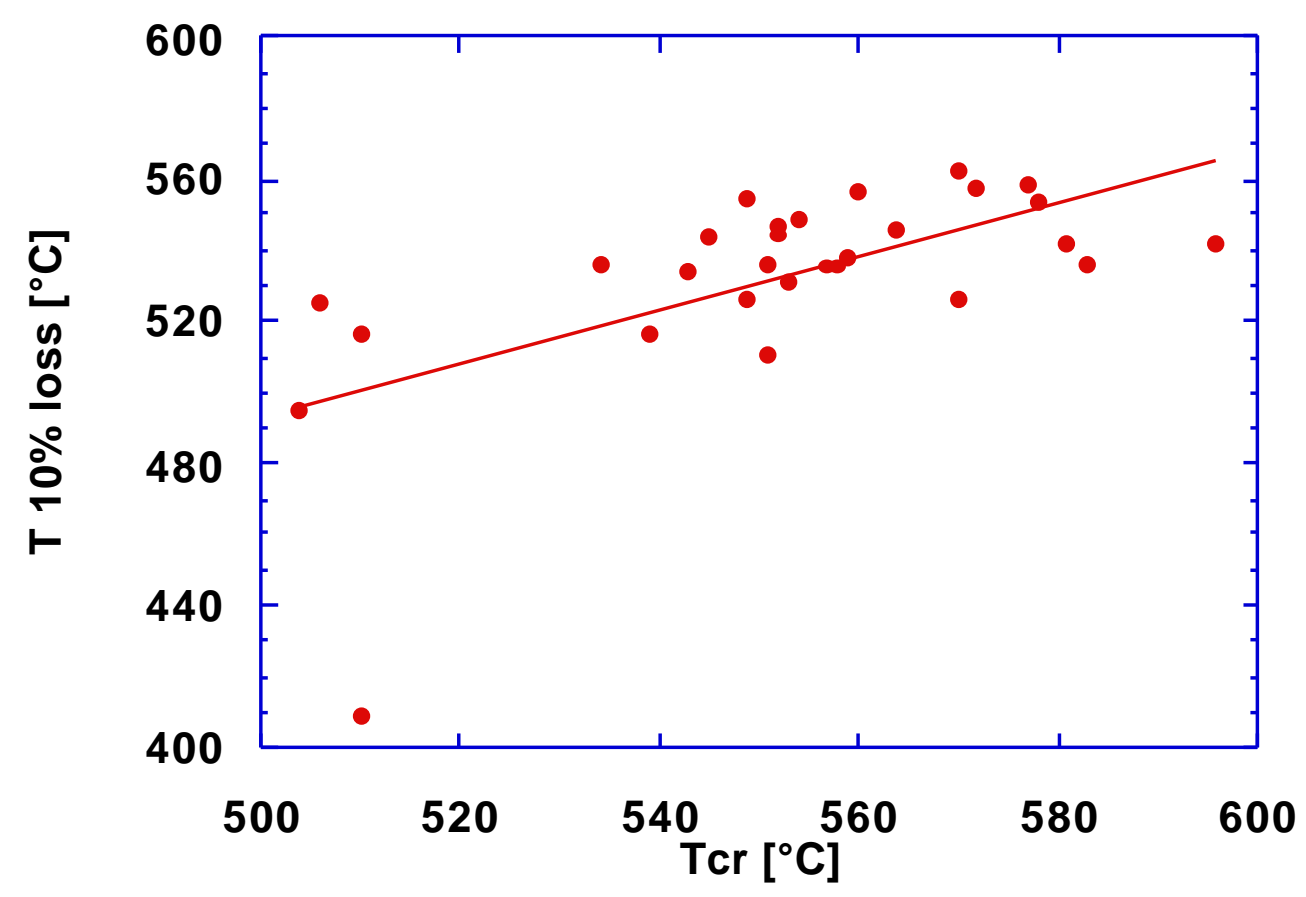

Figure 9. Comparison of temperature at which $10 \%$ mass loss was achieved with critical temperature.

It is apparent that the critical temperature is similar to, but often a bit higher than, the temperature at which about $10 \%$ of the carbon in the sample has been burned off. It is striking to note how narrow a range of critical temperatures is observed. The values are all in a range consistent with the earlier published values for coal chars whose oxygen and hydrogen contents 
had achieved very low values ${ }^{14}$. This suggests that the process of combustion in the residual chars is not very different than that observed with coal chars much earlier in the combustion process. This implies that annealing of the chars during combustion could, to a good approximation, be successfully modeled on the basis of hydrogen and oxygen loss from the char.

Figure 10 shows that there is no correlation between LOI and the critical temperature.

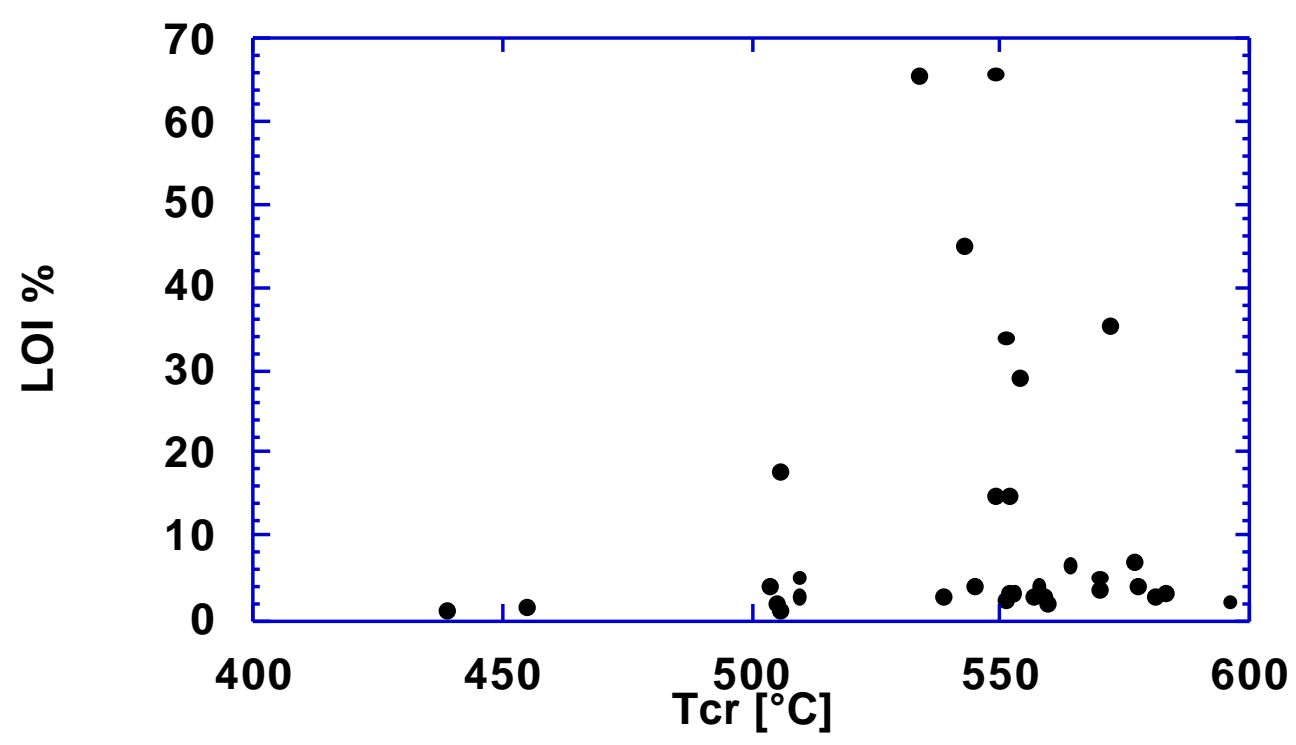

Figure 10. The relationship between reactivity (as measured by $T_{c r}$ ) and residual carbon in the fly ash (as measured by LOI). Note that $T_{\text {cr }}$ is the inverse of reactivity - the higher $\mathbf{T}_{\mathrm{cr}}$, the lower reactivity.

It has likewise been difficult to discern any correlation between the carbon surface area and the critical temperatures. Were the inherent reactivities per unit of sample surface equal, then the surface areas would be decisive in determining the value of critical temperature, as measured reactivity would simply be proportional to accessible area. The fact that this is not the case suggests that other factors (such as active site density, catalysis) play a significant role in determining the measured critical temperature. 
Figure 11 shows that there is likewise no obvious correlation between the results of Foam Index testing and reactivity as measured by critical temperature. Thus how active the fly ash carbon is towards adsorption of AEA does not correlate with how reactive it is towards oxygen. Most of the fly ash carbons have rather similar surface areas, so the small reactivity differences would be attributable to small chemical structural differences in the carbons themselves. The significant differences in AEA adsorption behavior can be understood in terms of differences in polarity of the surfaces, which depends upon the degree to which oxides were kept on the surface at the moment the carbons were quenched. There would not necessarily be a link expected between the steady state reactivity of the carbon, and its surface polarity.

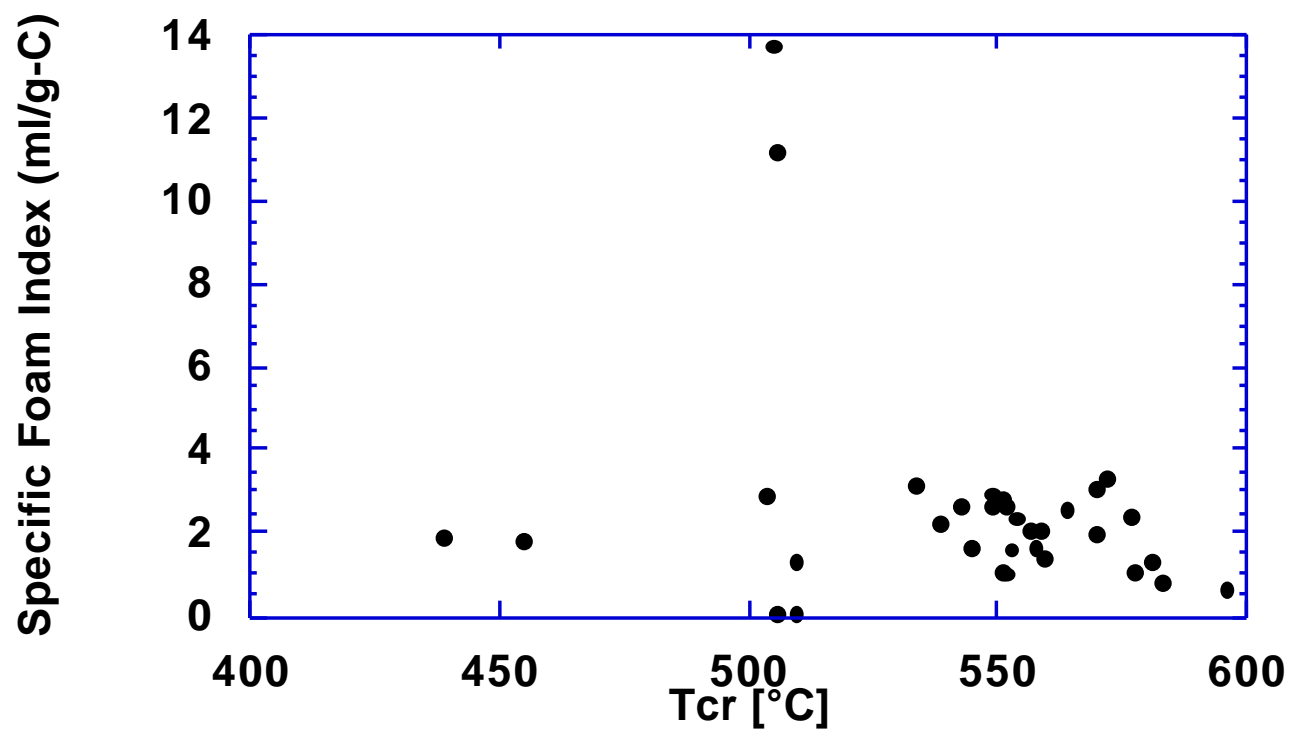

Figure 11. Relationship between carbon reactivity (as measured by $\mathbf{T}_{\mathrm{cr}}$ ) and the specific foam index.

It is also interesting to compare the sample which gave good concrete performance and which had a polar surface (FA 5) with that exhibiting poor performance and non-polar surface (FA 6). This comparison shows that the former exhibits somewhat lower reactivity $\left(\mathrm{T}_{\mathrm{cr}}=596^{\circ} \mathrm{C}\right)$ than the latter problem ash $\left(\mathrm{T}_{\mathrm{cr}}=570^{\circ} \mathrm{C}\right)$. It is not surprising to find a change in nature of the carbon, associated with a change in firing conditions (in this case FA 5 and FA6 were pre- and post-low 
NOx retrofit, respectively). But again, it is not believed that the difference in reactivity is itself responsible for the difference in concrete performance, since there appeared to be no general trend when a broader range of samples was considered. The change in the reactivity of the carbon instead reflects a change in firing conditions, which in turn is somehow related to the change in surface oxidation state of the fly ash when it exits the boiler. It is this oxidation state which can strongly affect the adsorption potential for AEAs, because it affects the surface polarity.

A preliminary comparison was also performed on samples prepared by separation of fly ash by the STI electrostatic technique. Comparison of samples FA 22, the parent ash, with the concentrate prepared from that ash, FA 23, showed the reactivities to be virtually identical (critical temperatures were 551 and $549{ }^{\circ} \mathrm{C}$, respectively). Thus the ability of separation technologies of this kind to prepare ashes which are acceptable for concrete use is likely attributable to removal of carbon to a sufficiently low level, as opposed to removal of a specific type of carbon (at least as can be judged by this indirect test).

\subsection{CONCLUSIONS}

During this period, attention has been turned to characterization of the carbon in fly ash as a porous adsorbent. Nitrogen and carbon dioxide isotherms have been used to confirm that the carbons are highly microporous. The surface area contained in micropores is presumably responsible for the AEA adsorption which renders certain fly ashes unsuitable for use in concretes, but this area may be useful in other adsorption applications. Not all fly ash carbons contain such microporous surface area; fly ashes containing unburned petroleum coke contain little such area, and cannot adsorb any significant amounts of AEA. The fact that surface area alone is not sufficient as a characterization of fly ash suitability has also been reaffirmed by results which show that different fly ash carbons of comparable surface area exhibit widely differing capacities for AEA adsorption. The postulated role of surface polarity of the carbon has thus again received support. 


\subsection{REFERENCES}

1. Tyson, S. and Blackstock, T., Proc. Unburned Carbonaceous Material on Utility Fly Ash Conference, page 30, U.S. Dept. of Energy, April, 1995.

2. Fitzgerald, H., Chumley, J. and Waldrop, R., Proc. Unburned Carbonaceous Material on Utility Fly Ash Conference, p. 2, U.S. Dept. of Energy, April, 1995.

3. Hemmings, R.T., Venta, G.J., Golden, D.M., Proc. Unburned Carbonaceous Material on Utility Fly Ash Conference, p. 15, U.S. Dept. of Energy, April, 1995.

4. Gao, Y.-M., Shim, H.-S., Hurt, R.H., Suuberg, E.M. and Yang, N.Y.C., Energy and Fuels, 11, 457, 1997.

5. Freeman, E., Gao, Y.-M., Hurt, R.H., and Suuberg, E.M., Fuel, in press.

6. Helmuth, R. Fly Ash in Cement and Concrete, Portland Cement Association, 1987.

7. Groszek, A., Carbon, 25, 717 (1987).

8. Greenbank, M., Matviya, T., Tramposch, W., Proc. 21st Conf. Carbon, p. 369, Am. Carbon Society, 1993.

9. Randtke, S., Snoeyink, V., J. Am. Water Works Assoc., 75, 408 (1983).

10. Sabanegh, N., Gao, Y.-M., Suuberg, E.M., Hurt, R.H., "Interaction of Coal Fly Ash with Concrete Surfactants - Diffusional Transport and Adsorption”, Proc. 1997 ICCS, p. 1907, DGMK, Essen, Germany, 1997.

11. Smith, K.A., Külaots, I., Hurt, R.H., Suuberg, E.M., “The Chemical Nature of Unburned Carbon Surfaces in Fly Ash - Implications for Utilization in Concrete”, Proc. 1997 Int. Ash Utilization Symp., p. 650, University of Kentucky, 1997.

12. Gregg, S.J. and Sing, K.S.W., Adsorption, Surface Area and Porosity, Academic Press, 1982.

13. Rodríguez-Reinoso, F. and Linares-Solano, A., Chemistry and Physics of Carbon, 21, p. 1, P. Thrower, Ed., Dekker, 1989.

14. Charpenay, S., Serio, M.A., Solomon, P.R., 24th Symp. (Int.) on Comb., p. 1189, The Combustion Institute, Pittsburgh, 1992. 